\title{
O emprego do endomarketing em cooperativas de crédito: Estudo de caso da UFV-Credi ${ }^{1}$ e da Unicred-Viçosa ${ }^{2}$
}

\section{The use of endomarketing in credit unions: A case study of the UFV- Credi and the Unicred-Viçosa}

\author{
Marcelo José Braga ${ }^{3}$ \\ Antonio João Hocayen da Silva ${ }^{4}$ \\ Henrique Lopes Dornelas ${ }^{5}$
}

\begin{abstract}
Resumo
O Endomarketing pode ser conceituado como um conjunto de atividades voltadas para o interior da organização, cuja finalidade é valorizar o ser humano. Para que as cooperativas de crédito sejam competitivas, elas devem adotar estratégias de Endomarketing, que combinem elementos de motivação, treinamento e comunicação. Procurou-se com o presente estudo, verificar como a Cooperativa de Economia e Crédito Mútuo dos Servidores da Universidade Federal de Viçosa - LTDA / UFV-CREDI e a Cooperativa de Economia e Crédito Mútuo dos Médicos e demais Profissionais da Saúde de Viçosa Ltda - UNICRED/VIÇOSA-MG estão utilizando as ferramentas oferecidas pelo Endomarketing. Na metodologia foi realizado um estudo acerca do Endomarketing e das cooperativas de crédito, para posteriormente realizar a aplicação de questionários aos funcionários e aos cooperados das cooperativas. Após a análise dos dados obtidos, chegou-se a conclusão de que a UFV-CREDI e a UNICRED/ VIÇOSA-MG estão conseguindo atingir os seus objetivos de forma eficaz, pois suas estratégias de Endomarketing têm apresentado resultados positivos, permitindo que as mesmas consigam captar novos cooperados bem como manter os seus cooperados e os seus funcionários motivados e satisfeitos com os produtos e serviços oferecidos pelas cooperativas.
\end{abstract}

Palavras-chave: Cooperativas de Crédito, Endomarketing, Estratégias.

\begin{abstract}
Endomarketing can be considered as a group of activities concerned with the internal aspects of the organization, whose purpose is to value the human being. In order to become competitive, the Credit Unions should adopt Endomarketing strategies that combine motivation, training and communication elements. The purpose of the present work was to verify how the Credit Union of the Workers of the Federal University of Viçosa Ltd. / UFV-CREDI and the Credit Union of the Doctors and Health-related Professionals of Viçosa Ltd. - UNICRED/VIÇOSA - MG are using the tools offered by Endomarketing. In the methodology, a study concerning the Endomarketing and the Credit Unions war carried out. After that, the employees and the members of the Credit Unions were asked to answer a questionnaire. After the analysis of the obtained data, it was concluded that UFV-CREDI and UNICRED/VIÇOSA-MG have effectively reached their objectives because their Endomarketing strategies have presented positive results, making it possible for them to get new members as well as to keep their members and employees motivated and satisfied with the products and services offered by the Credit Unions.

Key words: Credit Unions; Endomarketing; Strategies.

${ }^{1}$ Cooperativa de Economia e Crédito Mútuo dos Servidores da Universidade Federal de Viçosa LTDA.

${ }^{2}$ Cooperativa de Economia e Crédito Mútuo dos Médicos e demais Profissionais da Saúde de Viçosa LTDA.

${ }^{3}$ Prof. Dr. Coordenador do Curso Administração de Cooperativas, Departamento de Economia Rural - DER, Universidade Federal de Viçosa - UFV. mjbraga@mail.ufv.br

${ }^{4}$ Bacharelando em Administração de Cooperativas, Departamento de Economia Rural - DER, Universidade Federal de Viçosa UFV.eg38552@mail.ufv.br

${ }^{5}$ Bacharelando em Direito, Departamento de Direito - DIR, Universidade Federal de Viçosa - UFV. hldornelas@ig.com.br
\end{abstract}




\section{Introdução}

Com o aumento da concorrência no ambiente econômico e a necessidade de satisfação dos clientes, as empresas tem buscado estratégias que lhes permitam manter sua posição competitiva no mercado, estando nesse sentido, inserida uma efetiva administração de marketing.

O marketing, ao longo da história cresceu sobre a égide dos bens de consumo e das empresas que visam ao lucro, mas possui grande importância, também, para os problemas com que se defrontam as organizações que não visam ao lucro, uma vez que todas elas dependem de relações de troca para conseguir os recursos de que necessitam, para converter tais bens e serviços eficientemente à disposição da sociedade.

Tendo por base esses aspectos, salienta-se a necessidade do marketing aplicado às cooperativas de crédito, de modo que as mesmas ao procederem nesse plano, sejam capazes de desenvolver uma pesquisa de mercado que lhes ofereça indicativos de como as demais instituições disponibilizam tais serviços, ao mesmo tempo em que mostre ao cooperado as vantagens que a cooperativa lhe oferece em detrimento das demais instituições bancárias.

De acordo com dados da Organização das Cooperativas Brasileiras (OCB), o cooperativismo brasileiro tem passado por um crescimento significativo, estando atualmente registrado um total de 6.094 cooperativas, distribuídas nos diversos segmentos do sistema cooperativista. Este crescimento apresentouse acentuado a partir da década de 1980 , sendo que em décadas anteriores o mesmo era estável (ORGANIZAÇÃO DAS COOPERATIVAS BRASILEIRAS, 2001).

De acordo com o gráfico 1 a seguir, na década de 1980, surgiram 766 novas cooperativas, por sua vez, na década de 1990 surgiram 3340 novas cooperativas, o que representou um surgimento de $430,41 \%$ novas cooperativas, em relação às surgidas na década de 1980.

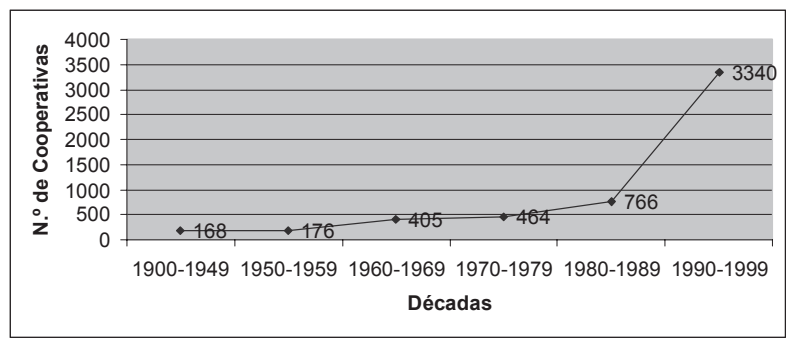

Fonte: Organização das Cooperativas Brasileiras. Núcleo de Banco de Dados (2001).

Gráfico 01: Evolução quantitativa das cooperativas, por década de fundação.

Para que as cooperativas de crédito possam realizar suas tarefas e servir a seus associados se faz necessário conhecer o ambiente em que estão inseridas, quais são seus clientes em potencial em sua área de atuação e determinar o tamanho ótimo da empresa. Para tanto é preciso que a empresa faça seu planejamento, avalie seus funcionários e dirigentes e mostre que a inter-relação empresa/mercado é necessária para a obtenção de informações para que se avaliem as potencialidades da empresa em atingir o seu público-alvo.

Ao proceder tal análise vários aspectos serão relevantes, uma vez que a cooperativa tem uma identidade diferente e apresenta uma estrutura participativa e assim ao adequar tais atividades de marketing, as mesmas serão adaptadas à filosofia da instituição e talvez se faria necessário intitular tais atividades por um outro nome de modo a diferenciar o marketing que será implementado, pois este será um marketing cooperativista.

O trabalho tem por objetivo, realizar uma análise das estratégias de endomarketing adotadas pelas cooperativas de crédito, verificando os modelos e suas implicações sobre este tipo de empreendimento, utilizando para avaliação, indicativos econômicos e sociais apresentados pelas cooperativas. 


\section{Referencial teórico}

\subsection{Cooperativismo de crédito}

Atualmente, o cooperativismo de crédito tem se tornado um dos ramos de maior destaque dentro do sistema, pois tem assumido uma grande importância nesse processo de economia globalizada e disputa de mercado.

Segundo Pinho (1996, p.42):

as características peculiares das cooperativas de crédito são os juros mais baixos que o praticado pelo mercado, estrutura enxuta, custos operacionais inferiores aos praticados no mercado financeiro, realização das operações ativas (empréstimos de dinheiro) apenas com os associados, linhas de crédito destinadas às atividades de seus cooperados, sejam elas específicas da profissão ou atividades econômicas que aglutinam.

As cooperativas de crédito praticam também operações acessórias, como prestação de serviços (cobrança de títulos, recebimentos e pagamentos, etc.) e operações de custódia. Praticam ainda as chamadas operações especiais, consubstanciadas na aplicação financeira de recursos eventualmente ociosos, que visam preservar o poder de compra da moeda.

Segundo Pinho (1996, p.47):

o patrimônio dos associados da cooperativa de crédito está protegido contra qualquer ato de dilapidação. A legislação declara que o patrimônio pessoal dos dirigentes responde pelos seus atos de improbidade, como ocorre com todas as instituições financeiras. Os processos por improbidade são rigorosos e sumários. Os estatutos trazem, por força da lei, salvaguardas efícazes, tal como a ação constante do Conselho Fiscal. E dessa forma, conjugadas com a ação fiscalizadora do Banco Central, estão garantidas a segurança e a tranqüilidade do associado.

No caso de insucesso do empreendimento, o associado só responde pelos compromissos da cooperativa até o montante do capital subscrito, assim mesmo, se for exigido judicialmente da própria cooperativa, porque elas são constituídas na forma de responsabilidade limitada.
As cooperativas de crédito e auxílio mútuo captam seus recursos no meio social e os reaplicam na própria área de atuação, impedindo o fluxo negativo que ocorre com os bancos, que, por exemplo, captam recursos no meio rural e os aplicam no meio urbano, ou mesmo captam recursos em determinada região urbana e os aplicam em outros municípios, conforme a demanda de sua clientela.

As cooperativas concentram os recursos obtidos em prol do seu próprio quadro social, com a redistribuição das disponibilidades, fortalece o processo produtivo da área onde está inserida, ou seja, o município ou a região que abrange.

A ação da cooperativa resulta no fomento da produção e torna o processo uma dinâmica constante, pois os resultados positivos dos financiamentos retornam multiplicados como novas captações da cooperativa de crédito. Nesse ciclo, haverá, cada vez mais, maior liquidez e mais recursos para reaplicação na sua atividade alvo.

\subsection{Importância do marketing no sistema cooperativista}

Segundo Kotler, (1993, p.11), “o marketing pode ser conceituado como uma atividade humana direcionada para satisfazer necessidades e desejos por meio de processos de troca, sendo que seus conceitos centrais são necessidades, desejos, demandas, produtos, troca, transações e mercados".

O marketing combina atividades de pesquisa de mercado, definição de preço, propaganda, estudo da viabilidade, entre outros, sendo que, as mesmas buscam proporcionar satisfação aos consumidores e cooperados, o que consequentemente, colabora para que a sociedade cooperativa consiga atingir os seus objetivos.

$\mathrm{O}$ endomarketing pode ser definido como marketing interno, sendo que este implica que a empresa de serviços deve treinar e motivar seus funcionários que contatam os clientes e todo o pessoal de apoio ao serviço como um time para proporcio- 
nar satisfação ao cliente. $\mathrm{O}$ endomarketing deve preceder ao marketing externo, pois não adianta o oferecimento de excelentes produtos ou serviços antes que os funcionários da organização estejam prontos ou preparados para proporcioná-los aos clientes (KOTLER, 1993, p.416).

As cooperativas de credito adotam estratégias de endomarketing, haja vista que as mesmas estabelecem relações com seus cooperados, e que neste caso, quanto maior a movimentação e a participação dos cooperados com a cooperativa, maiores os benefícios para a mesma. A cooperativa de crédito para manter-se, necessita da participação dos cooperados de forma ativa, devendo para isso adotar estratégias que estabeleçam a satisfaçam do cooperado ou, então, o menor custo pelo serviço oferecido, ou ambos, para assim atingir seus objetivos e manter-se atuante (PINHO, 1996, p.45).

\subsection{Endomarketing em sociedades cooperativas}

Os atos praticados pelas sociedades cooperativas são denominados atos cooperativos, e são aqueles praticados entre a cooperativa e seus cooperados, e entre cooperativas que tem o mesmo objeto social, sendo que estes não representam operação de mercado, ou seja, a sociedade cooperativa estabelece relações com seus cooperados, através de um sistema eficaz de comunicação entre ambos, buscando a atuação e participação ativa destes junto à sociedade, pois esta depende de transações, aplicações, depósitos dos cooperados para manter-se em funcionamento.

Segundo Cerqueira Neto (1994, p.49), “o endomarketing significa marketing voltado para dentro da empresa, ou seja, consiste em um conjunto de ações e veículos de comunicação integrados para que os funcionários tenham e saibam de sua importância para alcançar o sucesso".

Os sistemas de endomarketing visam atingir uma linguagem cultural própria e homogenia em todo o empreendimento, fazendo com que todos, indepen- dentemente do nível hierárquico possam se comunicar e trazer benefícios para a organização.

O papel da comunicação dentro de uma organização é de suma importância para que todos possam cumprir suas tarefas com eficiência, criando um feedback constante, gerando eficácia no trabalho desenvolvido e realização dos objetivos propostos.

\subsection{Objetivos do endomarketing}

Os principais objetivos do endomarketing são: i) Manutenção de um ambiente de trabalho, que proporcione motivação, valorização e reconhecimento das pessoas; ii) Aumento dos índices de produtividade e qualidade com a diminuição dos custos; iii) Criação de canais de comunicação entre todos, independente do nível hierárquico, para a eliminação de conflitos interpessoais e também para trocas de experiências, gerando assim uma melhoria nos relacionamentos (KOTLER, 1993, p.417).

Dentro do conceito de endomarketing, pode-se observar que este trabalha com a motivação, o treinamento, e a comunicação.

O processo de comunicação pode ser entendido de acordo com Mello (1970, p.34), como:

um processo de transmissão e de recuperação de informações, sendo que tem como elemento orientador o fluxo que modela a estrutura do processo. Esse fluxo compreende dois estágios distintos: a transmissão e a recuperação. No entanto, é necessário perceber que, apesar de diferentes em sua natureza, esses dois estágios apresentam uma interação cíclica, refletindo, assim, o dinamismo constante do processo de comunicação.

$\mathrm{O}$ treinamento no endomarketing inclui aspectos de atitude e de valorização do funcionário, estimulando suas perspectivas dentro do empreendimento, merecendo atenção especial os treinamentos ligados a atendimentos, clientes, objetivos e métodos, comprometimento, entre outros.

Segundo Carvalho (1997, p.154), “o treinamento constitui-se num processo de ajudar o empregado 
a adquirir eficiência no seu trabalho presente ou futuro, através de apropriados hábitos de pensamento e ação, habilidades, conhecimentos e atitudes". Os objetivos do treinamento são a modificação do comportamento profissional do treinando, o desenvolvimento do espírito de integração por parte da equipe de trabalho e o desenvolvimento das aptidões de liderança.

O trabalho de endomarketing consiste também na criação de ambientes e situações que façam o funcionário a ter motivação em seu trabalho, trabalhando com as questões motivacionais.

Segundo Chiavenato (1995, p.65):

torna-se difícil definir exatamente o conceito de motivação, sendo que este tem sido utilizado em diferentes sentidos. De modo geral, motivo é tudo aquilo que impulsiona a pessoa a agir de determinada forma ou, pelo menos, que dá origem a uma propensão a um comportamento específico.

Existem diversos fatores internos e externos que influenciam o comportamento humano dentro das organizações, dentre eles, o mais importante é a motivação humana, sendo este explicado através do ciclo motivacional, que pode ser completado com a efetivação de uma satisfação, ou uma frustração, ou ainda com a compensação das necessidades humanas.

A motivação pode ser caracterizada como um processo intrínseco ao indivíduo, que o impulsiona, que o leva a atuar, a comportar-se de determinada maneira em direção ao mundo exterior. Neste norte, é de fundamental importância a aplicação de estratégias de motivação dentro da cooperativa, através do endomarketing (BERGAMINI, 1988, p.30).

\subsection{Endomarketing e participação no cooperativismo}

A participação é um fator primordial para que se possa gerir uma empresa cooperativa com efetividade, pois é através da participação efetiva das pessoas envolvidas no processo, que se torna possível o alcance dos objetivos propostos.
É o que aborda Oliveira (1996, p.18), quando diz que,

a participação é talvez o principal fator de eficiência empresarial sob o ponto de vista políticosocial nas cooperativas. Não obstante ser mais complexa e difícil à tomada de decisão sob condições de democracia, sua solidez e comprometimento social é infinitamente maiores.

Ao estudar a participação social em cooperativas é necessário saber o que vem a ser participação, bem como a realidade desta participação na cooperativa, analisando a importância desse tema para a administração da mesma.

A participação social tem sido um tema muito discutido por vários autores da área de cooperativismo e de outras áreas, como a administração. O sentido que se coloca, ao discutir a participação nessas áreas, está voltado, de forma geral, apenas para o envolvimento do "pessoal" em atividades planejadas pela administração ou diretoria. A idéia é de que a contribuição individual possa favorecer o desempenho global da organização, de forma eficiente e eficaz. A contribuição, no caso das cooperativas de crédito, refere-se a recursos advindos da movimentação de capital pelos associados, através de empréstimos, conta corrente, poupança e demais serviços. Assim, a participação adquire um caráter formalístico, em que os indivíduos apenas cumprem papéis específicos na organização, ou seja, a participação é reduzida a uma prática burocrática, estando longe de ser empregada em seu real sentido.

Nesta linha de raciocínio, Cruz (1987, p.148) considera que, "a participação é aparente, tendo como função apenas legitimar as decisões tomadas".

Para Rios (2000, p.54), a participação pode ser analisada em dois níveis que se interpenetram: subjetivo e objetivo.

No nível subjetivo, a participação é entendida como identificação do associado com a cooperativa a que pertence como co-proprietário, isto é, ele não a vê como uma entidade de fulano ou sicrano, mas a vê como uma entidade pela qual também se sente 
responsável e diretamente interessado. No nível objetivo a participação é entendida como freqüência e atuação em Assembléias da cooperativa, integralização do capital subscrito, realização de operações econômicas com a cooperativa e percepção de retorno, ocorrendo sobras no exercício financeiro.

O que pode ser observado, através dos vários estudos sobre o cooperativismo brasileiro, é que a pratica da participação tem sido apenas burocrática ou formalística, de cunho eminentemente tutorial, como foi descrito anteriormente. Neste sentido, como exemplo, podemos ilustrar a existência da figura do "dono da cooperativa", isto é, a pessoa que administra os negócios da cooperativa, única a definir a política da mesma, tomar decisões, manter contatos com bancos e órgãos de assistência técnica.

A participação tem um caráter de mudança social e faz-se necessário que todos os envolvidos no processo tenham em mente sua essencialidade e importância e procurem aplicá-la em sua efetividade, resultando em ações por parte de todos e permitindo assim a prosperidade da cooperativa.

\section{Metodologia}

Foram realizados dois estudos de casos, nos quais abordou-se as sociedades cooperativas de crédito do município de Viçosa/MG, UFV-CREDI e UNICRED. Através da aplicação de questionários aos cooperados e aos funcionários das cooperativas, buscou-se analisar, por meio de variáveis que refletissem no treinamento de funcionários, motivação dos cooperados e dos funcionários, participação dos cooperados e comunicação interna estabelecida entre funcionários e cooperados, cooperados e diretoria e funcionários e diretoria, como essas cooperativas têm utilizado as ferramentas oferecidas pelo endomarketing, para manterem-se competitivas e ampliarem suas posições no mercado.

Para a obtenção de dados foram utilizados dois modelos de questionários, um destinado aos funcionários e o outro aos cooperados. Na UFV-CREDI,
50 (cinqüenta) cooperados e todos os funcionários (09), responderam aos questionários, totalizando 59 (cinqüenta e nove) questionários preenchidos nesta organização. Na UNICRED/Viçosa, 39 (trinta e nove) cooperados e todos os funcionários (05), responderam aos questionários, totalizando 44 (quarenta e quatro) questionários preenchidos.

Os questionários foram aplicados no período de 17 de março a 28 de maio de 2001, em ambas as cooperativas, simultaneamente. Com o intuito de avaliar o interesse dos cooperados acerca dos acontecimentos internos nas cooperativas, os questionários foram deixados nas mesmas sob a responsabilidade dos gerentes, estes disponibilizaram os questionários aos cooperados, de forma aleatória, para que eles próprios procedessem o preenchimento sem a intervenção de outras pessoas. Para estabelecer o monitoramento da situação, os pesquisadores realizavam duas visitas semanais às cooperativas, nas quais recolhiam os questionários respondidos e verificavam o andamento da aplicação dos questionários de acordo com as orientações iniciais passadas aos gerentes.

Este procedimento foi adotado devido a pouca disponibilidade de tempo dos pesquisadores para realizarem uma abordagem direta aos cooperados, pois, para isso seria necessária a permanência dos mesmos na cooperativa por algumas horas durante o dia, o que por sua vez seria inviável, haja vista, que o trabalho contou com a participação de apenas três pesquisadores. Outra dificuldade encontrada, foi a baixa freqüência com que os cooperados compareciam a sede da cooperativa.

As sociedades cooperativas UFV-CREDI e UNICRED/Viçosa foram escolhidas para objeto de estudo devido ao fato de serem organizações recentes, pois as mesmas ainda não possuem 10 anos de fundação, e são organizações que estão em franco crescimento no setor.

Por serem as duas únicas cooperativas de credito do município de Viçosa/MG, fez-se necessário o desenvolvimento do trabalho com ambas, pois as- 
sim, pode-se ter maior confiança nos resultados obtidos, apresentando conclusões mais concretas.

\subsection{Caracterização da Cooperativa de Econo- mia e Crédito Mútuo dos Médicos e demais Pro- fissionais da Saúde de Viçosa Ltda. - UNICRED/ VIÇOSA-MG}

A Cooperativa de Economia e Crédito Mútuo dos Médicos e demais Profissionais da Saúde de Viçosa LTDA. (UNICRED/Viçosa-MG), foi constituída no dia 09 de dezembro de 1993, na cidade de Viçosa, e deu início às suas atividades no dia 25 de março de 1994, contando inicialmente com a participação de 25 sócios fundadores.

Como toda cooperativa de crédito, a UNICRED/ Viçosa-MG funciona à maneira de um banco e, como tal, está sujeita às normas do Banco Central. Esta executa as seguintes atividades: i) operações passivas que estão relacionadas aos depósitos e compensações de cheques de seus associados e funcionários; ii) operações ativas que dizem respeito a empréstimos, sendo que tais empréstimos podem ser para custeio da produção ou para investimentos; e iii) operações assessórias referentes ao pagamento de carnês e impostos.

A cooperativa procura conquistar novos cooperados e satisfazer os que já possui, oferecendo serviços de crédito pessoal, financiamentos variados, pagamento de impostos (IPVA, IPTU, IRRF), pagamento de contas (água, luz, telefone), cheque especial, plano de saúde, aplicações financeiras, entre outros.

A cooperativa tem por objetivo promover a educação cooperativista, a assistência financeira e prestação de serviços a seus associados, oferecendo-lhes produtos e serviços próprios ou resultantes de convênios específicos com organismos oficiais ou privados, através da ajuda mútua, da economia sistemática e do uso adequado do crédito, dentro das normas que regem as operações ativas, acessórias e especiais. Procurará, ainda, por todos os meios, fomentar a expansão do cooperativismo de economia e crédito mútuo.
A área de ação da UNICRED/Viçosa-MG está limitada ao município sede e aos municípios de Araponga, Abre Campo, Acaiaca, Amparo da Serra, Barra Longa, Canaã, Cajurí, Caputira, Coimbra, Diogo de Vasconcelos, Divinésia, Dom Silvério, Ervália, Guaraciaba, Jequerí, Matipó, Paula Cândido, Pedra do Anta, Piedade de Ponte Nova, Porto Firme, Ponte Nova, Raul Soares, Rio Casca, Rio Doce, São Miguel do Anta, Santa Cruz do Escalvado, Santo Antônio do Grama, São José do Goiabal, São Pedro dos Ferros, Sem Peixe, Teixeiras e Urucânia.

Através de reforma estatutária, a UNICRED procedeu à abertura do quadro social, passando o mesmo a ser composto por profissionais das seguintes categorias: i) médicos que exercem suas atividades na área de ação da cooperativa, com registro em vigor no CRM, estando na plenitude de sua capacidade civil, concordam com o estatuto e preenchem as condições nele estabelecidas; ii) excepcionalmente, as pessoas jurídicas conceituadas como micro e pequenas empresas, que tem por objetivo as mesmas ou correlatas atividades econômicas das pessoas físicas ou, ainda, aquelas sem fins lucrativos cujos sócios integrem obrigatoriamente o quadro de associados da cooperativa; e iii) os empregados da cooperativa.

Atualmente o quadro social da cooperativa é composto por 168 médicos, 8 pessoas jurídicas, 15 profissionais de outras áreas de saúde, 6 empregados da UNICRED ou de outras empresas associadas e 1 dependente de associado (esposa, filho, pais).

\subsection{Caracterização da Cooperativa de Econo- mia e Crédito Mútuo dos Servidores da Univer- sidade Federal de Viçosa Ltda. UFV-CREDI}

A Cooperativa de Economia e Crédito Mútuo dos Servidores da Universidade Federal de Viçosa LTDA./UFV-CREDI foi constituída em 26 de junho de 1998 dando início às suas atividades em 23 de novembro de 1998 foi criada pela associação de 44 professores e funcionários da Universidade. A princípio contava com um número pequeno de associa- 
dos, hoje são exatos 1050. Desde sua criação até hoje passou por uma metamorfose imposta pelo seu crescimento precoce, uma vez que ela associa uma média de 1,45 pessoas por dia, o que exige uma maior capacidade de organização enquanto instituição. A cooperativa foi criada com o intuito de prestar assistência financeira e serviços aos seus associados, mediante ajuda mútua, economia sistemática e o uso adequado do crédito, dentro das normas específicas que regem suas ações.

Para atender sua finalidade social, a cooperativa procura estimular a poupança e desenvolver programas de assistência financeira e de prestação de serviços creditícios aos seus associados, oferecer adequado atendimento aos cooperados quanto às suas necessidades de crédito, procurando torná-los independentes de outras instituições financeiras e fomentar a expansão do cooperativismo de economia e crédito mútuo na comunidade.

As pessoas são levadas a associar-se a UFVCREDI pelas facilidades oferecidas pela mesma, como: empréstimos, aplicações financeiras, antecipação salarial, desconto de cheques, conta corrente, poupança, pagamento de contas de água, luz, telefone, boletos bancários e compra de vale transporte. Com esses serviços, a UFV-CREDI procura suprir as necessidades de seus cooperados.

A área de atuação da cooperativa está limitada às dependências da Universidade Federal de Viçosa UFV/MG, e o ingresso na mesma é permitido apenas aos servidores da Universidade.

De acordo com informações extraídas do estatuto da cooperativa, pode-se definir a estrutura formal estabelecida hierarquicamente através de um conselho diretor, com um diretor presidente, encarregado de dirigir e supervisionar todas as atividades da cooperativa, um diretor administrativo, que cuida da parte funcional da cooperativa e de um diretor financeiro, que delibera sobre as finanças. $\mathrm{O}$ quadro de funcionários da cooperativa é composto por seis pessoas, sendo elas, o gerente, dois escriturários, um contador e dois caixas. No que tange a questão da dinâmica organizacional, notamos que o relacionamento formal se dá a partir do momento em que decisões tomadas pela diretoria são passadas para os funcionários, os quais cumpre de forma prédefinida.

Informalmente, é importante frisar que a maioria dos funcionários é ou foram estudantes da mesma faculdade o que gera um relacionamento informal, trazendo para o ambiente de trabalho um clima descontraído, ocasionado por meio de afinidades advindas de longos períodos de amizade, tanto entre funcionários quanto diretores, uma vez que estes foram professores daqueles.

\section{Resultados e discussões}

Após a aplicação dos questionários nas cooperativas de crédito mútuo de Viçosa/MG, UNICRED/ Viçosa-MG e UFV-CREDI, obteve-se uma gama de dados referentes às mesmas, que depois de tabulados e analisados, apresenta-se de forma que evidenciam algumas características peculiares de ambas organizações.

Dentre essas características nota-se que o grau de escolaridade apresentado pelos funcionários das cooperativas é elevado, haja vista que, dos 14 funcionários que representam o universo total de funcionários das duas cooperativas, $57 \%$ possuem $2^{\circ}$ grau completo, $29 \%$ possui $3^{\circ}$ grau completo e $14 \%$ destes, possuem $3^{\circ}$ grau incompleto, o que indica que o quadro de funcionários das cooperativas é formado por pessoas dotadas de capacidades gerenciais e administrativas, contribuindo para o desenvolvimento das mesmas.

A remuneração dos funcionários nas cooperativas varia entre 01 salário mínimo e 05 salários mínimos, apenas um certo número de funcionários recebe acima de 05 salários mínimos, sendo que cada cargo desenvolvido na cooperativa é remunerado de acordo com as funções desenvolvidas, o grau de complexidade das mesmas e o nível hierárquico ao qual o mesmo pertence. A remuneração dos funcionários 
nas cooperativas em estudo apresenta-se da seguinte forma: $29 \%$ dos funcionários recebem de 01 a 02 salários mínimos, outros $29 \%$ recebem acima de 05 salários mínimos, e os $42 \%$ restantes ganham de 02 a 05 salários. No que se refere ao motivo que levou o funcionário a trabalhar na cooperativa, para $62 \%$ dos funcionários foi a indicação de amigos ou cooperados, para $25 \%$ o fator determinante foi à perspectiva de promoção, e para $13 \%$ foi o salário oferecido pelas cooperativas.

As organizações devem procurar desenvolver mecanismos que objetivem trabalhar ou desenvolver a motivação em seus funcionários, pois os mesmos apresentam-se como peças-chave para o sucesso das mesmas.

Com relação à motivação interna nas cooperativas, nota-se que, ao contrário do que muitos pensam, o salário não é tido pelos funcionários como um instrumento motivador, como algo que os estimule a desenvolver suas tarefas de forma eficiente e satisfatória, e sim o ideal cooperativista. De acordo com a figura 01 , o ideal cooperativista é tido por $42 \%$ dos funcionários como o principal fator de motivação no trabalho, os demais $29 \%$, estão motivados pelo clima de camaradagem e outros $29 \%$ por perspectivas de promoção.

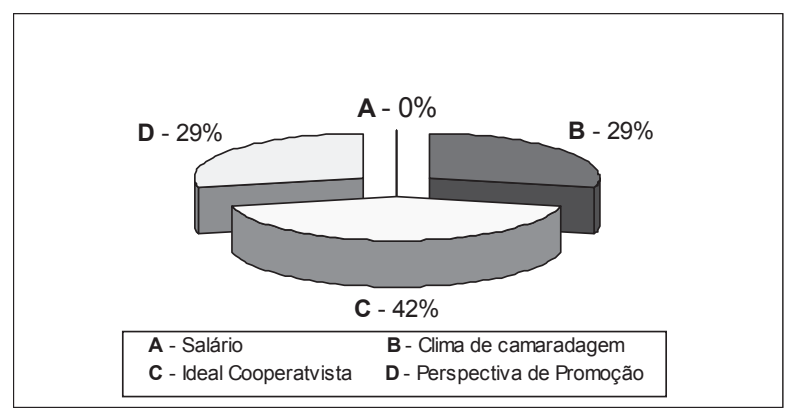

Figura 01: Fatores de motivação dos funcionários no ambiente de trabalho.

A satisfação dos funcionários com relação ao ambiente de trabalho é tida como uma das maiores causas de sucesso ou insucesso nas organizações, pois, em um ambiente que não oferece as condições favoráveis para o desenvolvimento de qualquer ati- vidade, os funcionários apresentam-se desmotivados e insatisfeitos, deixando de colaborar para o crescimento da organização. Na UFV-CREDI e na UNICRED/Viçosa-MG, nota-se que, com relação à satisfação dos funcionários, $86 \%$ deles apresentamse satisfeitos com o seu ambiente de trabalho e $14 \%$ estão insatisfeitos; $86 \%$ dos funcionários apresentam-se satisfeitos com a direção da cooperativa, e $14 \%$ dos funcionários não respondeu a esta questão, o que sugere que os mesmos estão insatisfeitos com a direção da cooperativa.

A existência de $14 \%$ de funcionários nas cooperativas insatisfeitos com o ambiente de trabalho, pode ter sido causada pelo fato de que as cooperativas não promovem a distribuição de prêmios entre os funcionários, procurando estimular o comprometimento dos mesmos com o trabalho e valorizando o bom trabalho desenvolvido por outros funcionários. De acordo com os dados obtidos, $71 \%$ dos funcionários das cooperativas, diz nunca ter recebido prêmios pelo bom desenvolvimento de suas tarefas nas cooperativas e apenas $29 \%$ afirmam ter recebido ou estar recebendo prêmios, da cooperativa, por tal realização.

A comunicação interna, entre os funcionários, apresentada nas cooperativas é tida por $57 \%$ dos funcionários das mesmas como uma comunicação boa, que atende às suas necessidades, para $29 \%$ dos funcionários, a comunicação estabelece-se de forma regular, e para $14 \%$ dos funcionários está estabelecese eficientemente (Figura 02).

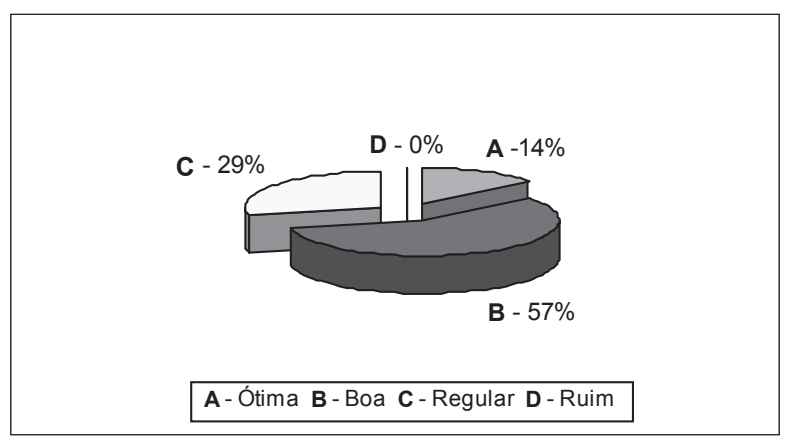

Figura 02: Comunicação entre os funcionários da cooperativa. 
A comunicação desenvolvida na cooperativa entre os funcionários e a diretoria da mesma, é tida por $72 \%$ dos funcionários como boa, para $14 \%$ dos funcionários a comunicação apresenta-se ótima e os $14 \%$ restantes dos funcionários a consideram como regular (Figura 03).

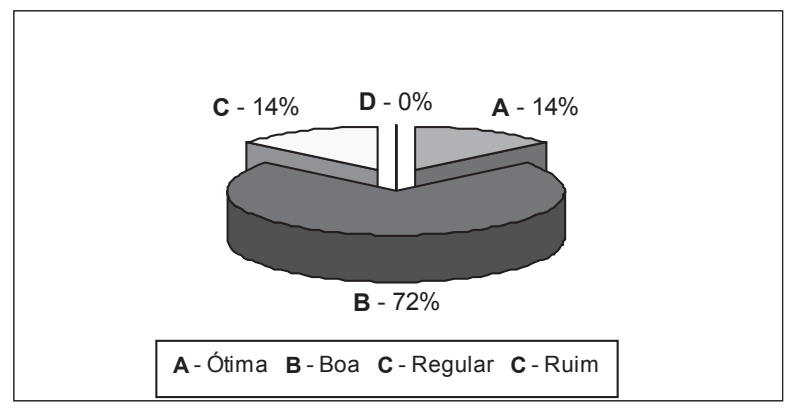

Figura 03: Comunicação entre funcionários e diretoria da cooperativa.

Entre cooperados e funcionários, a comunicação se estabelece de forma eficaz, pois, de acordo com a figura $04,57 \%$ dos funcionários a consideram como ótima, e $43 \%$ dos funcionários a reconhecem como boa.

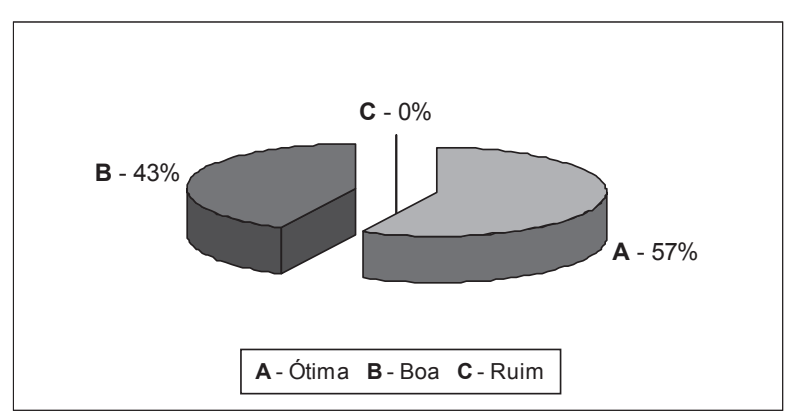

Figura 04: Comunicação entre cooperados e funcionários.

O problema referente à falta de comunicação entre os funcionários, entre cooperados e funcionários, e entre cooperados e diretoria, nas cooperativas em estudo, de acordo com $71 \%$ dos funcionários, ocorre ou ocorreu poucas vezes, e para os outros $29 \%$ dos funcionários, a ocorrência de tal problema nunca existiu. No processo de comunicação das cooperativas, as informações são transmitidas em $71 \%$ dos casos de forma direta, e em $29 \%$ dos casos através de reuniões.
Com relação ao treinamento oferecido, aos funcionários, pelas cooperativas, visando o aprimoramento das atividades desenvolvidas pelos mesmos, a difusão de conhecimentos sobre o sistema cooperativista e a melhoria do atendimento prestado aos clientes/cooperados, nota-se, que, de acordo com a figura $05,57 \%$ dos funcionários até a presente data, nunca realizaram cursos sobre cooperativismo, e apenas $43 \%$ dos funcionários já realizaram cursos que ofereciam o desenvolvimento de conhecimento sobre cooperativismo.

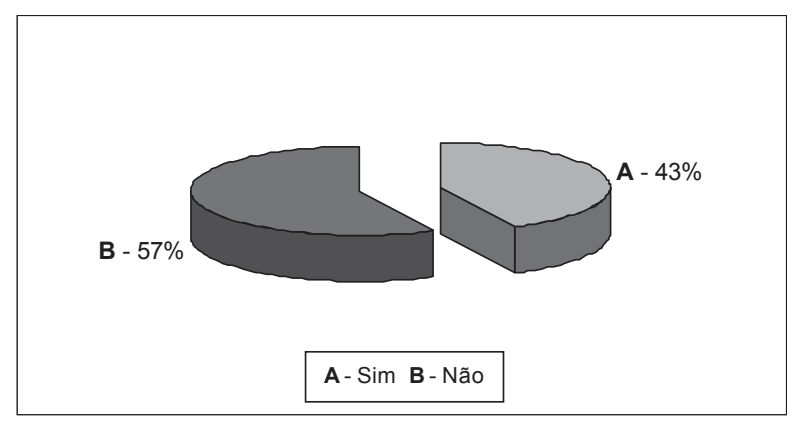

Figura 05: Número de funcionários que realizaram cursos sobre cooperativismo.

Com relação à participação em cursos que oferecem conhecimentos, aos funcionários, de técnicas de atendimento aos clientes/cooperados, temos que $86 \%$ dos funcionários já realizaram cursos para aprimorar tais técnicas e $14 \%$ não realizaram nenhum curso que possuía este fim (figura 06).

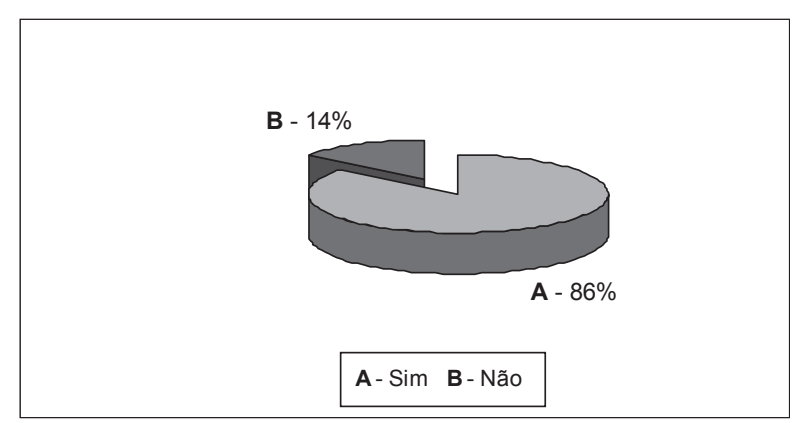

Figura 06: Número de funcionários que realizaram cursos para atendimento aos clientes/cooperados.

De acordo com os dados, pode-se ver ainda, que $71 \%$ dos funcionários possuem a necessidade de realizar cursos sobre cooperativismo e cursos para o 
aprimoramento das técnicas de atendimento a clientes/cooperados, e apenas $29 \%$ consideram que esta necessidade não existe, e que não é necessário que a cooperativa promova tais cursos.

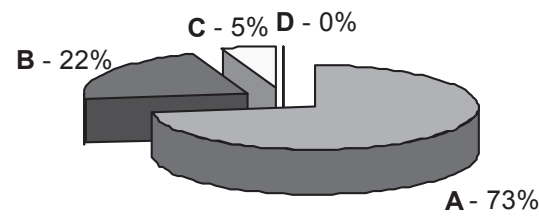

A - Ótimo B-Bom C-Regular D-Ruim

Figura 07: Qualidade dos serviços prestados pelas cooperativas aos seus cooperados.

De acordo com a figura 07 , observa-se que $73 \%$ dos cooperados entrevistados consideram que os serviços prestados pela cooperativa apresentam ótima qualidade, proporcionando-lhes satisfação e superando suas expectativas; $22 \%$ dos cooperados consideram que a cooperativa presta-lhes bons serviços, atendendo suas necessidades e cumprindo seu objetivo, que é a prestação de bons serviços aos cooperados; $5 \%$ dos cooperados consideram regular os serviços prestados pela cooperativa, haja vista, que tais serviços apresentam algumas falhas, não atendendo de forma eficiente as necessidades dos cooperados. Nenhum dos cooperados entrevistados consideraram ruins os serviços prestados pelas cooperativa.

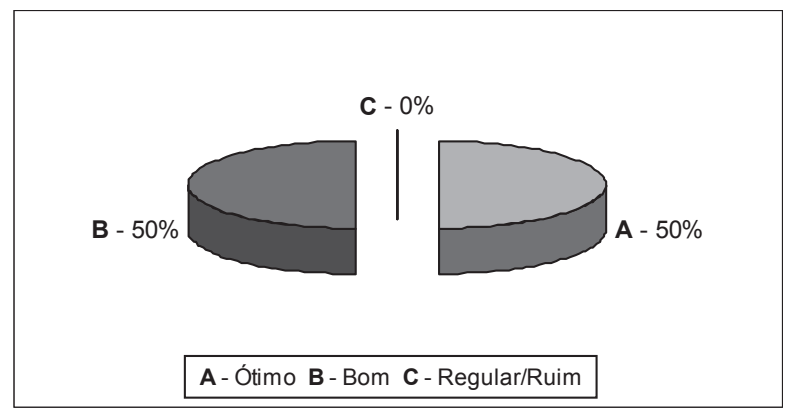

Figura 08: Relacionamento entre cooperados.

A figura 08 mostra que a cooperativa consegue sustentar um ambiente favorável ao relacionamento entre os cooperados, haja vista, que de acordo com
$50 \%$ dos cooperados o relacionamento estabelecido entre eles é ótimo, ou seja, de amizade, descontração, alegre e de muito respeito; e, outros $50 \%$ dos cooperados consideram este relacionamento como bom.

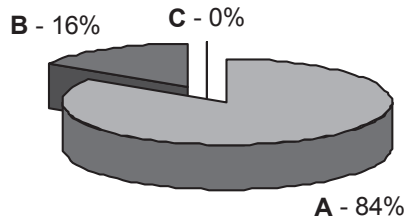

A - Superior B - Razoável C - Inferior/Péssima

Figura 09: Posicionamento da cooperativa frente aos bancos S/A, segundo os cooperados.

De acordo com a figura 09, observa-se que os cooperados confiam na organização a que pertencem, pois, $84 \%$ dos mesmos consideram que a cooperativa ocupa uma posição superior aos Bancos S/ $\mathrm{A}$, proporcionando-lhes vantagens que superam os serviços oferecidos pelos Bancos S/A; e, 16\% dos cooperados consideram que a cooperativa ocupa um posicionamento razoável em relação aos Bancos S/ A, mas que a mesma está caminhando para a superioridade. Não houve a ocorrência de casos que considerassem a posição da cooperativa inferior em relação ao Bancos S/A, o que possivelmente sugere que a cooperativa está atendendo as expectativas de seus cooperados.

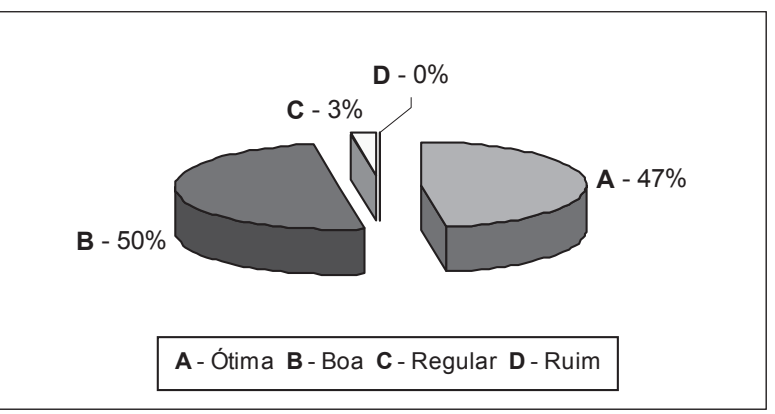

Figura 10: Primeiro contato dos cooperados com a cooperativa. 
De acordo com a figura $10,47 \%$ dos cooperados tiveram uma ótima impressão da cooperativa em seu primeiro contato com a mesma; $50 \%$ dos cooperados consideram que o seu primeiro contato com a cooperativa apresentou-se de forma boa; e, $3 \%$ dos cooperados tiveram um primeiro contato regular com a cooperativa.

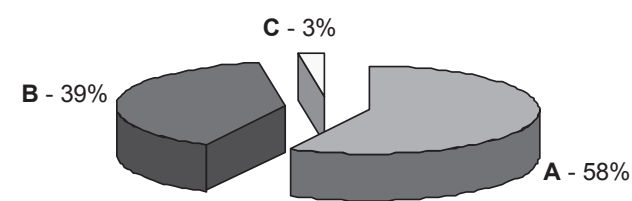

A - Trabalha B - Não Trabalha C - Não Respondeu

Figura 11: Índice de cooperados que realizam suas operações com outras instituições financeiras.

A fidelidade dos cooperados é crucial para o desenvolvimento e fortalecimento do empreendimento cooperativo, haja vista, que no caso das cooperativas de crédito especificamente os únicos clientes são os cooperados. De acordo com a figura 11 , notase que $58 \%$ dos cooperados entrevistados realizam operações com outros Bancos da cidade; 39\% dos cooperados não efetuam operações com outros Bancos, mantendo-se os mesmos fiéis à organização; e, $3 \%$ dos cooperados não responderam.

\section{Conclusões}

De acordo com o estudo realizado com a Cooperativa de Economia e Crédito Mútuo dos Médicos e demais Profissionais da Saúde de Viçosa LTDA./ UNICRED-Viçosa e da Cooperativa de Economia e Crédito Mútuo dos Servidores da Universidade Federal de Viçosa LTDA./UFV-CREDI, observa-se que quase a totalidade dos funcionários de ambas as cooperativas, apresentam-se satisfeitos com o ambiente de trabalho que as cooperativas lhes proporcionam, este ambiente propício ao desenvolvimento de suas atividades é reforçado pelo bom relacionamento existente entre funcionários e cooperados, cooperados e Diretoria e funcionários e Diretoria.
Um ponto positivo, elencado pelos funcionários, foi o clima de camaradagem existente entre eles e a diretoria das cooperativas, sendo o mesmo favorecido pelo fato dos funcionários e diretores serem amigos fora do ambiente de trabalho, o que pode ser concluído devido ao fato de que, $72 \%$ dos funcionários vieram a trabalhar na cooperativa por indicação de amigos ou cooperados.

Para os funcionários, de acordo com a figura 01 , o ideal cooperativista é o fator de maior motivação no trabalho, levando os mesmos, a desenvolver suas atividades com maior responsabilidade e dedicação, porém, ambas cooperativas não têm aproveitado este fato, haja vista que apenas $40 \%$ dos funcionários já participaram de cursos sobre cooperativismo, sendo que o mesmo é de fundamental importância para a compreensão do que é uma sociedade cooperativa e os seus objetivos. Diante disso, ambas cooperativas deveriam investir com maior afinco no treinamento de seus funcionários, desenvolvendo cursos sobre cooperativismo, o que tornará os funcionários capacitados acerca da constituição e do funcionamento das cooperativas, dessa forma os funcionários estariam mais motivados e envolvidos com o sistema cooperativista.

O treinamento dos funcionários, nas cooperativas em estudo, torna-se forte, no que se refere ao atendimento aos clientes, pois de acordo com os dados, nota-se que cerca de $80 \%$ dos funcionários das cooperativas, apresentam-se preparados para realizar um atendimento eficiente aos cooperados, haja vista que os mesmos já participaram ou estão participando de treinamentos para aprimorar suas técnicas de atendimento.

As estratégias de comunicação no ambiente interno e externo das cooperativas mostraram-se satisfatórias, sendo estabelecida de forma clara e contínua nas relações entre os próprios funcionários, entre funcionários e cooperados e funcionários e diretoria da cooperativa.

A circulação de informações de forma clara nas cooperativas, apresenta-se como um ponto positivo nas mesmas, pois a comunicação é de suma impor- 
tância para o desenvolvimento interno das cooperativas, propiciando agilidade na tomada de decisões, delimitação das competências e atribuições relacionadas aos funcionários, refletindo positivamente no relacionamento com os cooperados e nos resultados da cooperativa.

Com relação aos cooperados, de acordo com as informações obtidas, observa-se que estes estão satisfeitos com a atuação da cooperativa, pois os mesmos consideram que as mesmas desenvolvem suas atividades de acordo com as necessidades dos seus cooperados, atendendo assim os propósitos para os quais foram criadas.

O fato das cooperativas possuírem $58 \%$ dos seus cooperados realizando operações financeiras com outras instituições financeiras (Bancos S/A), torna o crescimento e o fortalecimento de ambas cooperativas mais lento, pois, as mesmas dependem das operações realizadas com seus cooperados. Sendo assim, essas cooperativas devem utilizar as ferramentas do endomarketing para desenvolver nos seus cooperados um espírito mais participativo e fiel à organização, para que os mesmos possam se envolver mais ativamente com os propósitos da cooperativa.

O maior interesse dos cooperados será obtido através de palestras e cursos sobre cooperativismo e a importância dos mesmos para a sobrevivência da cooperativa, ou ainda através de melhorias no ambiente interno da cooperativa, oferecendo aos seus cooperados serviços diferenciados, em relação aos serviços prestados por outras instituições financeiras e proporcionando-lhes maior reconhecimento.

Com a utilização das ferramentas de endomarketing, atreladas às características peculiares do Sistema Cooperativista, as Sociedades Cooperativas tornam-se mais capacitadas para atender de forma eficaz as necessidades de seus cooperados, tornando-os mais fiéis à organização e evitando que os mesmos realizem atividades com outras instituições, o que causaria uma redução no potencial de crescimento da cooperativa e um fortalecimento de seus concorrentes.

A pesquisa ateve-se em descrever e analisar as estratégias de endomarketing desenvolvidas pela
UFV-CREDI e UNICRED-Viçosa para a promoção de um ambiente favorável ao trabalho dos funcionários, ao relacionamento entre os diversos atores sociais que compõem a organização e à promoção da identificação cooperativas nos cooperados, buscando fortalecer a fidelidade dos mesmos com a cooperativa e torná-los agentes ativos no processo de tomada de decisão.

Desse modo, visando complementar o estudo realizado, observa-se a possibilidade de desenvolvimento de novas pesquisas, que tenham por objetivo analisar a relação entre a função social da cooperativa, que seria atender às necessidades dos cooperados, e as ferramentas do endomarketing, na busca do desenvolvimento social e na melhoria da qualidade de vida dos associados.

\section{Referências}

BERGAMINI, C. W. Avaliação do desempenho humano na empresa. São Paulo: Atlas, 1988. 290p.

CARVALHO, A. V. Administração de recursos humanos. São Paulo: Pioneira, 1997. 339 p.

CERQUEIRA NETO, E. P. Reengenharia do negócio. São Paulo: Pioneira, 1994. 178 p.

CHIAVENATO, I. Recursos humanos. São Paulo: Atlas, 1995. 525p.

CRUZ, T. R. Educação e organização social. Petrópolis: Vozes, 1987. $256 \mathrm{p}$.

KOTLER, P. Princípios de marketing. Rio de Janeiro: Prentice-Hall do Brasil, 1993. 478p.

MELLO, J. M. Comunicação social. Rio de Janeiro: Vozes. 1970. 318p.

ORGANIZAÇÃO DAS COOPERATIVAS BRASILEIRAS. Evolução quantitativa das cooperativas por década de fundação. Disponível em : <http://www.ocb.org.br>. Acesso em: 26 abr. 2001.

OLIVEIRA, C. C. J. A Avaliação da eficiência empresarial das cooperativas. Curitiba: OCEPAR, 1996. 80 p.

PINHO, D. B. Bases operacionais do cooperativismo. São Paulo: CNPq, 1996. 238 p. (Manual de Cooperativismo, v. 2).

RIOS, F. N. Cooperativismo como alternativa de mudança: uma abordagem normativa. Rio de Janeiro: Forense, 2000. 209 p. 
